NBER WORKING PAPER SERIES

\title{
UNEMPLOYMENT DISRUPTS SLEEP
}

David G. Blanchflower

Alex Bryson

Working Paper 27814

http://www.nber.org/papers/w27814

\author{
NATIONAL BUREAU OF ECONOMIC RESEARCH \\ 1050 Massachusetts Avenue \\ Cambridge, MA 02138 \\ September 2020
}

We thank Carol Graham, Jonathan Rauch, Chris Ruhm, Doug Staiger and Jonathan Skinner for helpful comments and suggestions. Alex Bryson thanks the Health Foundation for funding (grant number 789112) The views expressed herein are those of the authors and do not necessarily reflect the views of the National Bureau of Economic Research.

NBER working papers are circulated for discussion and comment purposes. They have not been peer-reviewed or been subject to the review by the NBER Board of Directors that accompanies official NBER publications.

(C) 2020 by David G. Blanchflower and Alex Bryson. All rights reserved. Short sections of text, not to exceed two paragraphs, may be quoted without explicit permission provided that full credit, including $(\subset$ notice, is given to the source. 
Unemployment Disrupts Sleep

David G. Blanchflower and Alex Bryson

NBER Working Paper No. 27814

September 2020

JEL No. I31,J64

\begin{abstract}
$\underline{\text { ABSTRACT }}$
Although there is a substantial literature indicating that unemployment and joblessness have profound adverse impacts on individuals' health and wellbeing, there is relatively little evidence of their impact on sleep. Using data for over 3.5 million individuals in the United States over the period 2006-2019 from the Behavioral Risk Factor Surveillance System (BRFSS) survey series we show sleep disruption patterns that vary by labor market status. We look at sleep measured by hours in a day and days in a month and whether sleep is disturbed over a fortnight, as indicated by problems falling or staying asleep or staying asleep too much. We find the shortterm unemployed suffer more short and long sleep than the employed and are more likely to suffer from disturbed sleep. These problems are greater still for the long-term unemployed and for the jobless who say they are unable to work.
\end{abstract}

David G. Blanchflower

Bruce V. Rauner Professor of Economics

6106 Rockefeller Hall

Dartmouth College

Hanover, NH 03755-3514

and NBER

David.G.Blanchflower@Dartmouth.EDU

\author{
Alex Bryson \\ Professor of Quantitative Social Science \\ UCL Social Research Institute \\ University College London \\ 20 Bedford Square \\ London WC1H 0AL \\ United Kingdom \\ a.bryson@ucl.ac.uk
}




\section{Introduction}

Unemployment hurts. We care about unemployment for several reasons: it increases susceptibility to malnutrition, illness, mental stress, and loss of self-esteem, leading to depression (Blanchflower, 2019). Being unemployed can reduce the life expectancy of workers. Increases in the unemployment rate tend to be associated with increases in the suicide rate. Unemployment increases the probability of poor physical health outcomes such as heart attacks in later life. Many of the unemployed delay life decisions such as marriage and having children. There is evidence of increases in smoking after unemployment. There is a great deal of evidence to suggest that unemployment is involuntary: unemployment makes workers unhappy.

Unemployment hurts and there is a deterioration of physical and mental well-being and skills for individuals who experience spells of unemployment, especially long ones. It is well known that unemployment can have harmful effects if durations are long and especially so if they happen when young (Ellwood, 1984). Young people who are unable to make the transition from school to work find it more difficult to strike out on their own and often end up living with their parents. The long-term unemployed also tend to earn less once they find new jobs (Nichols et al, 2013). Morale sinks as the duration of unemployment rises. Long spells of unemployment are especially harmful as the losses from unemployment worsen as the duration spell lengthens (Machin and Manning, 1999). The long-term unemployed are at a disadvantage in obtaining jobs. Long-term unemployment (LTU) was a major issue in Europe in the 1980s and 1990s when it rose sharply in European and most major OECD countries with the exception of Japan and the United States.

During the Great Recession long-term unemployment rose sharply around the world including in the United States. Krueger, Cramer and Cho (2014) note that the long-term unemployed have a 20 to 40 per cent lower probability of being employed 1 to 2 years ahead. Abraham et al (2019) confirmed that unemployment duration has a strong negative impact on the likelihood of subsequent employment and of lower subsequent earnings. They rule out the possibility that these long-term unemployed (LTU) individuals are "bad apples" and show they fare worse than the short-term unemployed (STU) more likely due to the state dependence explanation of the negative relationship between unemployment duration and subsequent success in the labor market. And yet, using data from 1987 to 2000 years of the Behavioral Risk Factor Surveillance System (BRFSS) Ruhm (2005) found that health often improves during an unemployment spell as unemployed workers get more exercise, smoke and drink less and lose weight.

There isn't much in the literature on the relationship between sleep and unemployment. The evidence that does exist is contradictory and focuses on the impact of macroeconomic labor market conditions on sleep duration. Using the American Time Use Survey (ATUS) Data from 20032012 Antillón et al. (2015) found that increases in the unemployment rate increased sleep duration: a 1 percentage point increase in unemployment is correlated with an extra 2.38 minutes of sleep. In contrast, Ásgeirsdóttir, and Ólafsson (2015) also using ATUS found no consistent relationship between unemployment and sleep duration. However, an inverse relationship between sleep duration and wages was found. The two papers used different dependent variables: the latter focuses on the overall amount of rest on the diary day, defined from 4 AM to 4 AM, whereas the former used the length of the longest continuous sleep episode. This might account for differences in the results. Neither explicitly examined the sleep duration of the unemployed themselves. 
Three other papers also used ATUS to look at sleep and work. Gibson and Schrader (2018) showed that increasing short-run weekly average sleep by 1 hour increased worker earnings by roughly 1\%. Niekamp (2018) found that economic expansions, where the unemployment rate falls, decreased weekday sleep but increased weekend sleep. Basner et al. (2007) found that increased working time reduced time spent sleeping.

Even though we know a lot about the consequences of unemployment, on future labor market activity and health and well-being its impact on the sleep of the unemployed is under-researched. Poor sleep may be the mechanism by which these disruptive effects of unemployment occur. Maeda et al (2019) found that in Japan unemployed men and women both had a higher likelihood of insomnia than the employed. Knabe et al (2010) using German data find that the unemployed sleep almost one hour longer than the employed. Asplund (2005) examined sleep in 1948 Swedes and found that poor sleep was associated with increased propensity for sick leave, while unemployment itself was associated with increased occurrence of poor sleep. However, they found from a logistic regression that unemployment was not independently associated with sleep impairment after adjustment for age, health, marital status and place of residence.

Virtanen et al (2013) caution that there is a potential for reverse causality from poor health and poor sleep to unemployment. They show that poor self-rated health and mood were good predictors of occurrence of unemployment and prolonged unemployment respectively. They found that the LTU were more likely to have musculoskeletal pain and poor sleep quality. But this is not likely to be the dominant relationship over the business cycle.

The "lockdown" in the spring of 2020 has generated a shock to the labor market and unemployment has risen sharply as activity slowed. In the United States the Department of Labor has shown that over 59 million workers filed initial unemployment claims between the week ending March $20^{\text {th }}$ and the week ending $20^{\text {th }}$ August $29^{\text {th }} 2020 .{ }^{1}$ The US Census Bureau has been conducting weekly Household Pulse Surveys tracking anxiety post Covid. ${ }^{2}$ In the period April 23 to May $5^{\text {th }} 36 \%$ of respondents said they had had anxiety "not at all" in the last 7 days. By July $6^{\text {th }}$ to July $17^{\text {th }}$ that had fallen to $11 \%$. The dominant relationship in 2020 is thus from unemployment to anxiety rather than the reverse.

We contribute to the literature by examining the association between labor market status and various aspects of sleep duration and quality, distinguishing between overall sleep duration in a 24-hour period, short sleep, long sleep and disturbed sleep as indicated by problems falling or staying asleep or staying asleep too much. We separate out the effects on both the STU and LTU as well of those in an increasingly important group who say they are 'unable to work' (Blanchflower and Oswald, 2020). We also have data on how many days per month respondents say they have insufficient sleep. We find the STU suffer more short and long sleep than the employed and are more likely to suffer from disturbed sleep. These problems are greater for the LTU and for the jobless who say they are unable to work.

\footnotetext{
${ }^{1}$ https://www.dol.gov/sites/dolgov/files/OPA/newsreleases/ui-claims/20201671.pdf
}

2 https://www.census.gov/programs-surveys/household-pulse-survey/data.html 


\section{Why should labor economists care about sleep?}

Inadequate sleep is mostly measured within a twenty-four-hour period (Chattu et al (2018); Altevogt et al (2006); Exelmans and Van den Buick (2016); Lockley et al (2004); Roehrs et al (1983)). But as we show below it can also be based on days in a month. Inadequate, or short sleep is associated with multiple poor life outcomes that impact daily functioning. It is known for example, that short sleep duration ( $<7$ hours per night) is associated with greater likelihoods of obesity (Wheaton et al, 2011a), diabetes (Shan, Ma and Xie et al 2015), coronary heart disease (Magee et al 2012, Wang et al, 2016, and Wu, Zhai and Zhang, 2014), depression, (Zhai, Zhang and Zhang 2015), hypertension (Wang, Mei, Jiang et al 2015), and death (Gallicchio and Kalesan, 2009). Insufficient sleep is also bad for social welfare: it can result in lost GDP and lower productivity (Hafner et al., 2017).

Perhaps less well-known is the evidence linking long sleep to poor health outcomes. Long sleep may also mean it is hard for the unemployed to engage in the sort of regular routine required by systematic job search, which is often a requirement of welfare receipt. Patel et al. (2006) found that multiple sclerosis, anti-depressant use, benzodiapine use and lupus were factors most strongly associated with long sleep. The traditional focus on short sleep is unsurprising since many more people suffer short sleep than they do long sleep (Knutson and Turek, 2006). However, a growing body of research establishes the health problems related to long sleep as well as short sleep. Bin et al. (2103) note that short and long sleep are both risk factors for morbidity and mortality. They find that short sleep predicts higher mortality, cardiovascular events, metabolic dysfunction, obesity, and poor mental health, while habitual long sleep predicts premature mortality, cardiovascular disease, and cognitive impairment. Buxton and Marcelli (2010) reported that both short and long sleep are positively associated with obesity, diabetes, hypertension, and cardiovascular disease among adults in the United States.

There are higher risks of mortality associated with both long and short sleep (Patel et al, 2004, Yin et al, 2017; Kronholm et al, 2011). In some studies, the association is even stronger in long than short sleep (Tamakoshi and Ohno, 2004, Kwok et al, 2018). Magee, Iverson and Caputi (2009) in a study of Australian adults found that short sleep was associated with long working hours and obesity while long sleep was associated with recent treatment for cancer, heart attack and angina. Short and long sleep are also associated with a higher risk of type-2 diabetes (Ferrie et al, 2015). Jike et al (2018) conducted a meta-analysis covering over 5 million respondents and found that long sleep was significantly associated with higher rates of mortality, diabetes, cardiovascular disease, stroke, coronary heart disease and obesity.

Changes in sleep duration are also found to affect health. Sleep deterioration had a negative effect on pain-related health outcomes (Afolalu, Ramlee and Tanga, 2018). An increase in sleep results in better outcomes such as sleep quality and a reduction in sleep medication (Tang et al, 2017). Sleep duration also affects subjective wellbeing: Piper (2016) shows a link between sleep duration and life satisfaction. Germans, he finds, sleep for seven hours a night, which is one hour less on average, than he calculates, from the German Socio-Economic panel of 2008-2012, is the level associated with maximal life satisfaction.

It is not surprising, therefore, that scientists have long studied sleep's correlates and antecedents. Part of this literature focuses on the links between sleep patterns and labor market status. The 
literature indicates that economic shocks affect sleep duration. Sleep duration is counter-cyclical (Colman and Dave, 2013). Nearly one-third of foregone work hours during the Great Recession were devoted to more sleep and TV watching (Aguiar et al., 2013).

An economic shock associated with job loss and subsequent unemployment is liable to impact an individual's sleep adversely, both indirectly through increased anxiety, depression and other health-related problems attendant on unemployment, but also directly having conditioned on health-related problems if, for example, the experience of unemployment impacts an individual's motivation and energy levels, or reduces the opportunity costs of sleep. To our knowledge, no studies to date assess the links between joblessness and various aspects of poor sleep. We do so distinguishing between short sleep and long sleep, as well as other measures of inadequate sleep such as inability to get to sleep, the number of days in the last thirty that the respondent felt they 'did not get enough rest of sleep', unintentionally falling asleep during the day, and having trouble falling asleep.

\section{Previous literature on sleep using BRFSS}

We analyse data from 2.5 million Americans from the Behavioral Risk Factor Surveillance System (BRFSS) survey series from 2006-2019. ${ }^{3}$ The BRFSS is a telephone survey conducted by the Center for Disease Control (CDC) regarding health-related risk behaviors, chronic health conditions, and use of preventive services. Established in 1984 with 15 states, BRFSS now collects data in all 50 states as well as the District of Columbia and three territories of the United States. In recent years around 400,000 adult interviews are conducted each year in the BRFSS. Questions vary over time. In some years only subsets of states field the relevant questions. The great advantage of these data over others used in the literature is that the sample sizes are substantially larger, making it easier for the analyst to establish robust relationships between sleep patterns and other factors in people's lives.

A series of studies have studied sleep patterns using BRFSS surveys, with a number focusing on the association with age. Liu, Wheaton et al (2013) used the 2010 BRFSS to examine short and long sleep using the following question:

\section{Q1. 'On average how many hours of sleep do you get in a 24-hour period?' (sleeptime).}

They examined data on 54,269 adults ages 45 and above and found that $31 \%$ of respondents age 45 and older reported being short sleepers ( $\leq 6$ hours), 65\% were optimal sleepers (7-9 hours), and $4 \%$ were long sleepers ( $\geq 10$ hours) in a 24 -hour period.

Using BRFSS 2014's Q1 question, Liu et al. (2016) found that the percent of adults ages 18-60 with $\geq 7 \mathrm{hrs}$ usual sleep followed a U-shape in age, minimizing between age 35 and 44 . Analogously, the proportion with short sleep defined as $<7$ hours followed an inverted U-shape with a maximum in the same age group of 35-44. Their results on the proportions with short sleep are reported below.

$$
\text { Ages } 18-24 \quad 32.2 \%
$$

\footnotetext{
${ }^{3}$ Excluding 2007. There is an overlap of data across years, so the 2018 file has some data for 2019. The data are downloadable at https://www.cdc.gov/brfss/annual_data/annual_data.htm
} 


$\begin{array}{ll}\text { Ages 25-34 } & 37.9 \% \\ \text { Ages 35-44 } & 38.3 \% \\ \text { Ages 45-64 } & 37.3 \% \\ \text { Ages } \geq 65 & 26.3 \% \\ \text { All } & 35.1 \% \\ \text { N } & 444,346\end{array}$

Grandner et al. (2012) used the 2006 BRFSS survey and examined responses on 155,877 participants on sleep disturbance over a fortnight. They found that sleep disturbances were especially high among the unemployed and those unable to work. The LTU had higher levels of complaints than the STU. We confirm this finding on later sweeps of the BRFSS.

The literature does suggest a note of caution when examining self-reported sleep duration data as exists in the BRFSS. It is well-known that self-reported sleep duration overestimates actual sleep duration. Girschik et al (2012) suggested that sleep questions typically used in epidemiologic studies do not closely correspond with objective measures of sleep as assessed using actigraphy. Lauderdale et al (2008) examined self-reports of hours of sleep for accuracy against measured sleep duration and found they were 'moderately correlated'. There could be various reasons for this. For example, it may be that the days when the subject wore an actigraph were atypical. It is unclear if there is any bias when respondents are asked about days in the month when they have had poor sleep.

However, the focus in this paper is principally on short sleep (under seven hours a night) and long sleep (ten hours or more). There is no evidence to our knowledge suggesting that misclassifications have a large effect on whether someone is classified as a short sleeper or a long sleeper. That is to say, the recall error would have to move an individual across these thresholds to have an impact on these results. In the presumably relatively rare event of this occurring it is unlikely to have any substantive impact on our results regarding links between labor market status and sleep. If someone actually sleeps for eight hours and actigraphy measured sleep as eight hours and five minutes that will impact sleep duration measures but will have no effect on our estimates of short or long sleep. Actigraph measures have not to our knowledge determined what sign it likely takes, let alone the size of the bias - it is unclear if people over or under-estimate sleep duration.

Furthermore, we do not simply rely on reported sleep durations to capture poor sleep or sleeping problems. We examine the BRFSS on sleep duration in twenty-four hours and then move on to the other measures of sleep or lack of it by the number of days in a month and a fortnight. It remains unclear if there is a bias in such data.

Liu, Croft et al (2013) examined self-reported sleep and chronic disease in 375,563 adults from the 2009 BRFSS based on days and focused on the number of days of insufficient sleep. They found a significant association between insufficient sleep, measured as at least half the days in a month with insufficient sleep - and six chronic diseases of diabetes, high blood pressure; coronary heart disease; stroke; asthma and arthritis. Wheaton et al (2011a) examined the 2008 BRFSS on 384,541 adults on sleep days in a month and found that days of insufficient rest or sleep strongly correlated with BMI. Perceived insufficient sleep was assessed by question Q2 in both studies. 
Q2. "During the past 30 days, for about how many days have you felt you did not get enough rest or sleep?" (qlrest2)

Defining insufficient sleep as at least 14 days the authors showed that this variable had an inverted $U$-shape in age $18-24=29 \% ; 25-34=36.0 \% ; 35-44=33 \% ; 45-64=26 \%$ and 65 and over $=14 \%$. They demonstrated a highly significant relationship between insufficient sleep and frequent mental distress (not good mental health days $>=14$ ), an indicator of psychological distress.

Despite all this work on sleep we know very little about the relationship between unemployment and sleep and especially between long and short sleep and unemployment. It is often assumed that, since the unemployed have more time available to them than the employed, and they are less constrained in how they spend that time - other than with regards to costly leisure pursuits - the opportunity costs of sleeping are lower and they will likely sleep more.

We contribute to this literature using observations on 3.5 million respondents in the 2006-2019 BRFSS to establish associations between labor market status and poor sleep including short sleep, long sleep and disturbed sleep.

\section{Results}

\subsection{Sleep duration in hours in a day, 2009-2019}

We begin with nationally representative data for the United States from eight sweeps of the BRFSS survey from 2009-2014, 2016, and 2018 using the hours of sleep in a day Q1 question described above. Several of the surveys also have a few observations from the prior year so there are some observations in 2014 from the 2013 survey and in 2015 from the 2014 survey, and so on.

The data for 2019 comes from the 2018 survey and the small sample for 2015 of under five thousand comes from the 2014 survey, and so on. The responses in the years prior to 2013 are drawn from sub-sample of states as below which were the only states that asked the questions in those years.

2009=Georgia; Hawaii; Illinois; Louisiana; Minnesota and Wyoming $2010=$ Arkansas; Connecticut; Delaware; DC; Hawaii; Illinois; Louisiana; Minnesota; Missouri; Nevada and Oregon.

2011= Alaska; Hawaii; Minnesota and Tennessee

2012=Alaska; Kansas; Nevada; Oregon; and Puerto Rico

In our BRFSS sample of over two million respondents, as can be seen below, hours of sleep average very close to seven hours per night in every year.

2009

2010

2011
Average hours of sleep

7.03 (35.0) [3.7]

$7.04(33.7)$ [3.9]

$7.01(35.0)[3.8]$
$\mathrm{N}$

36,829

46,244

22,230 


$\begin{array}{llr}2012 & 7.06(34.8)[4.6] & 24,854 \\ 2013 & 6.98(35.6)[3.6] & 478,811 \\ 2014 & 6.98(34.8)[3.6] & 458,992 \\ 2015 & 6.99(34.5)[3.3] & 4,770 \\ 2016 & 6.98(34.7)[3.4] & 466,777 \\ 2017 & 7.00(34.1)[3.3] & 62,529 \\ 2018 & 6.95(35.7)[3.5] & 413,998 \\ 2019 & 6.95(35.8)[3.1] & 18,737 \\ \text { Total } & 6.98(35.2)[3.5] & 2,034,771\end{array}$

Sample weights are used in calculating these mean estimates (using the variable, finwt). The numbers in round parentheses are the proportion of respondents that report less than seven hours of sleep per day. The proportion with short sleep ranges from $33.7 \%$ to $35.8 \%$, and averages $35.2 \%$ and has changed little over the decade or so examined. The numbers in square parentheses are the proportion of 'long sleepers' sleeping $>=9$ hours. There is an average of around $3.5 \%$ long sleepers per annum. Hence the number of short sleepers in the USA is ten times the number of long sleepers. The Census Bureau (https://www.census.gov/datatools/demo/idb/informationGateway.php) estimates that in 2018 , the last full year of sleep duration data that we have available, there were 262,140,772 adults age sixteen and over in the United States, which suggests there are around 92 million short sleepers and 9.2 million long sleepers. ${ }^{4}$

If we consider the relationship between sleep duration, long sleep and age we find a U-shape in duration and an inverse U-shape in short sleep. The weighted distribution of sleep hours by age is shown below using a sample size of 2,034,771, which minimizes in the age range $45-54$. The percent with short sleep maximises in the range 45-54 too.

$\begin{array}{lccc} & \text { Hours } & \text { \% short sleepers } & \text { \% long sleepers } \\ \text { Ages 18-24 } & 7.09 & 33.1 & 4.5 \\ \text { Ages 25-34 } & 6.87 & 38.3 & 2.7 \\ \text { Ages 35-44 } & 6.84 & 38.7 & 2.5 \\ \text { Ages 45-54 } & 6.82 & 39.0 & 2.6 \\ \text { Ages 55-64 } & 6.94 & 35.6 & 3.3 \\ \text { Ages 65-74 } & 7.21 & 28.2 & 4.5 \\ \text { Ages } \geq 75 & 7.42 & 24.8 & 7.2 \\ \text { All } & 6.98 & 35.2 & 3.5\end{array}$

Hours of sleep minimize in the age group 45-54. The percent of short sleeps maximizes in prime age (45-54). Long sleep minimizes in the age range 35-44. So, sleep duration and long sleep are U-shaped in age and short sleep is hill shaped in age. We explain this further below.

\footnotetext{
${ }^{4}$ Gallup has collected data on average sleep per night which they estimate fell from 7.9 hours in 1942 to 6.7 in 1990 and 2001 and 6.8 in 2004 and 2013. In 2013 they estimate that $40 \%$ were short sleepers (6 hours or less hours or less per night) versus $11 \%$ in $1942 .{ }^{4}$ In 1942 Gallup reported that $14 \%$ slept 9 hours or more versus $5 \%$ in 2013. that there was no significant change in sleep duration over the last 50+ years. Bin, Marshal and Glozier (2012) found in selfreported sleep duration data for adults across fifteen countries from the 1960s to the 2000s. Duration increased in 7 countries: Bulgaria, Poland, Canada, France, Britain, Korea and the Netherlands and had decreased in 6 countries: Japan, Russia, Finland, Germany, Belgium and Austria with no change for the United States and Sweden.
} 
Table 1 shows the overall distribution of (weighted) average hours of sleep by labor market status. Four fifths of the sample report sleeping between six and eight hours; 35.2\% are short sleepers. On average $3.5 \%$ are long sleepers, defined as 10 hours per night or more. The unemployed sleep more hours per day than workers do (6.95 hours per day for the LTU and 6.99 for the STU versus 6.87 for workers). However, both the STU and LTU are more likely than workers to experience both short sleep and long sleep. $36.6 \%$ of workers experience short sleep, compared with 37.7\% of the STU and $42.3 \%$ of the LTU. Only $0.6 \%$ of workers experience long sleep compared with $5.0 \%$ of the STU and $6.1 \%$ of the LTU.

In the top half of Table 2 we examine the percentage of short and long sleepers by disaggregated labor market status. Information is available both on short-term unemployment (STU) with a spell duration of less than a year and LTU with a spell of unemployment of at least a year. The data also contains details of another relevant category - unable to work - that accounts for $6.8 \%$ of the sample which is more than the two unemployment groups added together $(6.2 \%)$. We discuss this group in a separate section below. The table presents weighted means of the proportions with short and long sleep. ${ }^{5}$ Short and long sleep are both especially high for those who say they are unable to work. The link to being unable to work is consistent with other studies on the adverse effects of unemployment, such as Blanchflower and Oswald (2020) which showed those who were unable to work were especially likely to report being in despair.

To examine the independent association between labor market status and sleeping patterns further we turn to multivariate analyses. ${ }^{6}$

Table 3 presents estimates of sleep duration in a 24-hour period. There is a U-shape in age with year dummies alone (column 1) and with the addition of month and state dummies (column 2). Column 3 shows differentials in mean sleep duration by labor market status controlling for personal characteristics, year, month and state dummies. Both the STU and LTU have longer sleep durations than workers, whereas those who are unable to work have shorter sleep durations than employees. But that is not the whole story: we need to separate out normal sleep from disrupted sleep including whether it is long or short, as well as whether people have trouble falling or staying asleep.

Table 4 presents probit estimates of short and long sleep probabilities in a 24-hour period. In the short sleep equations, we omit long sleepers and vice versa for long sleepers. Hence, we compare short ( $<7$ hours) and long sleepers ( $\geq=10$ hours) in turn to normal sleepers, defined as 7-9 hours a night.

\footnotetext{
5 The CDC on its website reports data on short sleep, defined as less than seven hours a night using the 2014 BRFSS, and confirms that $35.2 \%$ of adults were short sleepers. Data on short sleep by state is available at https://www.cdc.gov/sleep/publications/factsheets.html

6 The BRFSS data files each year from 2011 were constructed by using information on landline and cell phones identified with the variable QSTVER. Values less than 20 indicate that the interview was conducted by landline phone, and 20 and higher indicate a cell phone interview. Most of the sample are cell phone users by 2018, as older persons are adopting cell phones in higher numbers. Cell phone use accounted for $19 \%$ of the weighted sample in 2011 compared with $76 \%$ in 2018 . In the regressions to follow we included a cell phone dummy which is set to zero in 2009 and 2010 and one in later years.
} 
Columns 1 reports the probability of short sleep relative to 'normal' sleep having dropped long sleepers, and contains labor market status only, while column 2 adds personal controls. The hump shape in age is apparent in both specifications. ${ }^{7}$ In both specifications the self-employed, homemakers, students and the retired are all less likely than the employed to experience short sleep, while the LTU and those who are unable to work are significantly more likely to suffer short sleep. The positive correlation between STU and short sleep in column 1 falls to zero with the introduction of controls.

Chart 1 shows the percentage of short sleepers by single year age bin among those who are either short or normal sleepers. It is hump-shaped in age for both the LTU and STU and tends to be more prevalent among the LTU across the lifecycle. ${ }^{8}$

Columns 3 and 4 of Table 4 report similar probit estimates, but this time for long sleep versus normal sleep. Long sleep is U-shaped in age, minimizing around the age of 50-52 years. Employees are less likely to be long sleepers than others, and this remains the case with personal controls. Those unable to work have the highest probabilities of being long sleepers, followed by the LTU, then the STU.

Chart 2 plots rates for long sleep excluding the short sleepers. The LTU have more long sleep than the STU at all ages, but the U-shape in age is not apparent.

\section{2: Insufficient sleep in days in a month, 2008-2012.}

We now turn to an alternative measure of poor sleep, namely the perception of having suffered from insufficient sleep. We examine data on this variable qlrest 2 defined as Q2 above, using the 2008 file used by Wheaton, Perry et al (2011); the 2009 file used by Liu, Croft et al (2013) plus the 2010-2012 files. Unweighted sample sizes are as follows $2008(\mathrm{n}=405,931) ; 2009$ $(n=425,022) ; 2010(n=435,781), 2011(n=25,891)$ and $2012(n=24,880)$. The data from 2011 and 2012 are taken from a sub-set of states as they are the only ones that fielded the relevant question. ${ }^{9}$ Sample size overall for the years $2008-2013$ is 1,317,505.

\footnotetext{
${ }^{7}$ Wheaton et al (2011b) from the CDC found similar evidence using the 2005-2008 National Health and Nutrition Survey (NHANES): in their study $37 \%$ of U.S. adults reported regularly sleeping $<7$ hours per night. Short sleep duration was more common among adults aged $20-39$ years (37\%) or 40-59 years (40\%) than among adults aged $\geq 60$ years $(32 \%)$.

${ }^{8}$ In the charts we plot the short rates vs normal excluding the long sleepers and long rates excluding the short sleepers. The overall rates are as follows.

Short vs normal Long vs normal

Employee $\quad 37.9 \quad 2.8$

Self-employed $\quad 32.6 \quad 3.9$

Out of work 1+ years $\quad 45.0 \quad 10.7$

Out of work $<1$ year $\quad 39.3 \quad 7.4$

Homemaker $\quad 30.9 \quad 5.9$

$\begin{array}{lll}\text { Student } & 32.4 & 5.2\end{array}$

$\begin{array}{lll}\text { Retired } & 27.5 & 7.3\end{array}$

Unable to work $\quad 56.2 \quad 18.9$

9 The 16 states with data on insufficient sleep for 2011 and 2012 were Alaska; California; Colorado; Hawaii; Illinois; Kansas; Louisiana; Minnesota; Nevada; New Mexico; North Carolina; Oklahoma; Oregon; Tennessee; Utah; Wisconsin plus Puerto Rico.
} 
It remains unclear the extent to which respondents over or underestimate the number of days in a month they had insufficient sleep. Actigraphy has tended to focus on inaccuracies in correctly recalling hours of sleep in a day rather than days in a month. This variable will pick up short sleepers, but long-sleepers may or may not report that they want even more sleep.

Overall, $31 \%$ of the sample said there were zero days in which they felt they did not get enough rest or sleep in the last 30 days, while $11 \%$ say every day. The mean number of days was 8.47 and $25 \%$ said fourteen days or more. The weighted distribution by age is as below $(n=1,310,155)$. The columns in turn refer to mean days; per cent with 14-30 days where the respondent did not get enough rest or sleep.

$\begin{array}{lcc} & \# \text { days } & >14 \text { days \% } \\ \text { Ages 18-24 } & 9.08 & 29.5 \\ \text { Ages 25-34 } & 10.37 & 34.6 \\ \text { Ages 35-44 } & 9.73 & 32.2 \\ \text { Ages 45-54 } & 8.96 & 28.9 \\ \text { Ages 55-64 } & 7.53 & 24.0 \\ \text { Ages 65-74 } & 5.18 & 15.8 \\ \text { Ages } \geq 75 & 4.48 & 13.8 \\ \text { All } & 8.47 & 27.5\end{array}$

In both cases there is a maximum in the age group 25-34 confirming the finding in Liu et al (2016) for the 14-30 days variable.

The second part of Table 2 presents average number of days and the proportion saying on a half or more days in the month they got insufficient sleep. The patterns are similar to those using hours in the first part of the table. The unemployed have more days of inadequate sleep but the unable to work category has the highest incidence.

Columns 1 and 2 of Table 5 estimate the number of days with insufficient sleep, with and without personal controls respectively, with the controls including a cubic in age to pick up a non-linearity at older ages (as depicted in Chart 3). Column 1 is an OLS regressions for the number of days of insufficient sleep in the last month and column 2 is a probit estimate for the probability of having insufficient sleep in at least 14 days in the last month. In column 1 the LTU experience significantly more days of insufficient sleep than employees as do those who are unable to work, whereas the STU experience significantly fewer. In column 2, when we look at whether half or more of the days in a month are days of insufficient sleep, the negative coefficient for the STU turns to insignificance.

\subsection{Disturbed Sleep: Trouble falling asleep, staying asleep or sleeping too much over a fortnight, 2006.}

The previous section used a question on insufficient sleep that was unlikely to pick up long sleepers unless they had long sleep and wanted more. It really focused on those who were unable to get 
enough sleep. However, the BRFSS 2006 contains a question (Q3) relating to disturbed sleep, whether it be because of too little sleep, difficulty falling asleep or too much sleep.

Q3. "Over the last 2 weeks, how many days have you had trouble falling asleep or staying asleep or sleeping too much?"

Grandner et al (2012) used this question and found that 54.3\% say zero days and $10.5 \%$ say all 14 with a mean of 2.87 days. Panel 3 of Table 2 reports restless sleep over the past fortnight by labor market status: employees reported 2.4 days, about half the rate of the STU and LTU, whereas those unable to work reported restless sleep for an average of almost 7 days.

Column 3 of Table 5 report the results of estimating an OLS equation with the dependent variable the number of days in a fortnight (fourteen days) of disturbed sleep. Given the question includes both long and short sleepers and even normal sleepers who might have restless sleep it is unsurprising to find that this measure of sleep declines with age.

Compared to employees the LTU, the STU and those unable to work have large and significantly positive coefficients, with the latter having the largest impact. That is also true in column 4 which models the probability, using a probit, of someone saying all 14 days were disrupted. There are again positive and significant effects for these three groups versus employees.

In the appendix we report OLS regression results using data from Eurobarometer Survey \#56.1 for 2001 that asked about disrupted sleep $(n=15,782)$. The question asked was as follows.

Q4. "Would you say that you have not at all (=1), no more than usual (=2), rather more than usual (=3), much more than usual $(=4)$... lost much sleep over worry?" with our coding in parentheses.

The unemployed enter significantly positively compared with workers and non-workers. Fishermen, business owners, Italians and the Greeks had especially high probabilities of losing sleep over worry.

In the UK there is evidence from the National Health Service of the age distribution of admissions to hospital for a primary diagnosis of sleep disorders by age in the London region. ${ }^{10}$ Over the financial years 2013/14-2017/18 there were a total of 33,000 hospital admissions. The distribution is as follows by age group as follows: $20-29=2910 ; 30-39=5230 ; 40-49=7415 ; 50-59=8260 ; 60$ $69=5945 ; 70-79=2885 ; 80$ and over $=620$. So, there is an obvious hump shape in age with the largest number of admissions of over 8000 admissions being in the age range 50-59. We don't know, however, whether the sleep problems were from too much or too little sleep. But, most bad sleep is short sleep, hence the hump shapes in age.

\section{4: Sleep Among Those Unable to Work}

\footnotetext{
${ }^{10} \mathrm{https}$ ://digital.nhs.uk/data-and-information/find-data-and-publications/supplementary-information/2018supplementary-information-files/hospital-admissions-for-sleep-disorders-covering-the-london-commissioning$\underline{\text { region }}$
} 
As noted above, in the BRFSS one of the labor market categories is "unable to work". As Blanchflower and Oswald (2020) have noted this has become an increasingly important category over time, especially for prime age (ages 35-54) less educated, defined as those with a high school diploma/GED or less. The data are as follows for those age under seventy. Overall, as a weighted proportion of the population it has nearly tripled from 1993 to 2020 and did not fall as the unemployment rate ticked down since 2009. In the 2019 survey unable to work accounted for one in eight of the prime age less educated. ${ }^{11}$ In contrast for this group unemployment accounted for $5.1 \%$.

\begin{tabular}{|c|c|c|c|c|c|c|c|c|}
\hline \multirow[b]{2}{*}{1993} & \multirow{2}{*}{$\begin{array}{l}\text { All } \\
2.7\end{array}$} & \multicolumn{2}{|c|}{$\begin{array}{l}\text { Prime age } \\
\text { less educated }\end{array}$} & All & \multicolumn{2}{|c|}{$\begin{array}{r}\text { Prime age } \\
\text { less educated }\end{array}$} & All & $\begin{array}{c}\text { Prime age } \\
\text { less educated }\end{array}$ \\
\hline & & 5.1 & 2003 & 4.8 & 9.3 & 2013 & 7.2 & 13.2 \\
\hline 1994 & 3.1 & 5.0 & 2004 & 5.0 & 9.1 & 2014 & 7.6 & 14.1 \\
\hline 1995 & 3.2 & 6.0 & 2005 & 5.2 & 9.6 & 2015 & 7.4 & 13.5 \\
\hline 1996 & 3.4 & 5.7 & 2006 & 5.2 & 10.2 & 2016 & 7.4 & 13.4 \\
\hline 1997 & 3.4 & 6.6 & 2007 & 5.5 & 11.2 & 2017 & 7.4 & 12.5 \\
\hline 1998 & 3.6 & 6.5 & 2008 & 5.5 & 10.7 & 2018 & 7.6 & 13.2 \\
\hline 1999 & 3.9 & 7.3 & 2009 & 5.6 & 11.3 & 2019 & 7.3 & 13.0 \\
\hline 2000 & 4.2 & 7.7 & 2010 & 5.8 & 11.4 & 2020 & 7.2 & 12.0 \\
\hline 2001 & 4.3 & 8.0 & 2011 & 6.9 & 13.0 & & & \\
\hline 2002 & 4.5 & 8.6 & 2012 & 7.1 & 13.3 & & & \\
\hline
\end{tabular}

Of note is that it remains unclear what these people are doing and whether they are actually sick, ill or disabled or not. In the 2019 BRFSS the unable to work reported that on average out of the last 30 days 11 were bad mental health days versus 7 for the unemployed.

Table 2 suggests that $9 \%$ of the unable to work reported being long sleepers and a half said they were short sleepers and a half said that they had insufficient sleep in the majority of the last 28 days. They had lower sleep durations in column 3 of Table 3 versus employees but this is because they were more likely to suffer short sleep than employees as well as suffering long sleep, with short sleepers dominating, also confirmed in Table 4.

Chart 4 is like Charts 1 and 2 in that it presents the incidence of short sleep among those who are short sleep or normal sleepers, and long sleep among those who are long or normal sleepers, but this time for those who are unable to work. Whilst there is some indication of a hump-shape in age for short sleep, long sleep appears constant across the life course.

Sleep disruption seems to be a major factor for those unable to work and even more so than the LTU. As Blanchflower and Oswald (2020) note the unable to work, especially those with low levels educated in prime age, are especially likely to report that all thirty of the past thirty days were bad mental health days.

The question is to what extent lack of sleep may have moved these folks from unemployment to out of the labor force (OLF). It is unclear what the 'unable to work' are actually doing. The labor

\footnotetext{
${ }^{11}$ The 2019 BRFSS was not included by Blanchflower and Oswald (2020) in their study as the data file only became available in September 2020. There are 18,650 observations in 2020, mostly in January.
} 
force participation rate (LFPR) of prime age, especially men has not returned to pre-recession levels. ${ }^{12}$ Of interest is the Council of Economic Advisors (2016) examined the long run decline in prime age male LFPR and found that the largest difference in how prime age men in and out of the labor force spend their time is in time spent on leisure activities-socializing, relaxing and leisure. Nonparticipating men spent almost twice as much time on these activities than prime-age men overall, and more than twice as much time watching television.

\section{Discussion and Conclusion}

This paper examines the relationship between labor market status and poor sleep. In contrast to previous studies we distinguish between five measures of sleep, namely sleep duration in a 24hour period, short and long sleep in a 24-hour period, insufficient sleep over a one-month, and disturbed sleep over a fortnight, as indicated by problems falling or staying asleep or staying asleep too much. We find the short-term unemployed suffer more short and long sleep than the employed and are more likely to suffer from disturbed sleep. These problems are greater for the long-term unemployed and for the jobless who say they are unable to work.

The findings have potentially serious implications for the jobless since both short and long sleep are linked to higher morbidity and mortality. In the 2019 BRFSS released in early September 2020 and covering the period from January 2019 through April 2020 we see the poor health of the unemployed and especially the unable to work on a number of dimensions below (weighted estimates).

\#bad mental health days last 30

\#bad physical health days last 30

Despair (30/30)

Depressive disorder diagnosed ever

$\mathrm{N}$ (on bad mental health days)
Workers

$$
3.7
$$

2.5

4.6

15.4

202,639
STU

7.1

4.7

11.1

28.4

7,600
LTU

7.8

6.7

15.2

31.5

7,983
Unable to work

10.7

15.1

21.8

49.1

Disparities in the mental and physical health of the jobless versus workers are huge. The period of worklessness appears to matter, too, with health problems becoming more pronounced as individuals leave STU for LTU and, in the extreme case, declare themselves "unable to work".

The recent pandemic is liable to take its toll on sleep especially if temporary layoffs turn into permanent ones and there is a second round of COVID infections. It may well be important to use what Blanchflower (2019) called 'the economics of walking about' to determine what is going on. There are already signs at the time of writing at the end of August 2020, that unemployment is rising again. Searches in the USA in Google Trends for the word "unemployment" picked up sharply in March 2020 before falling steadily. But from August $23^{\text {rd }}$ it started rising again. Recent research shows the lockdown response to COVID-19 in Italy increased sleep difficulties, particularly among those reporting higher levels of depression and anxiety (Cellini et al., 2020) and those reporting work-related troubles (Gualano et al., 2020). Similar increases in sleep

\footnotetext{
${ }^{12}$ According to the BLS the seasonally adjusted LFPR for men ages 35-44 was $92.1 \%$ in January 2008 at the start of the Great Recession versus 90.9 in February 2020. In contrast the rates for women 35-44 had returned - from 76.1\% to $76.5 \%$ respectively.
} 
difficulties linked to increased depression and anxiety have been linked to the COVID outbreak elsewhere too (eg. Falkingham et al., 2020 for the UK and Huang and Zhao, 2020 for China). Blume, Schmidt and Cajochen (2020) conducted a study of sleep after lockdown in March 2020 in Austria, Germany, Switzerland. They found that sleep durations rose, but sleep quality decreased, and they suggested that led to a decrease in physical and mental wellbeing as a result.

Prescriptions for sleep medications jumped $15 \%$ between mid-February and mid-March according to Express Scripts. ${ }^{13}$ According to a survey conducted in May 2020, 53\% of Americans said they spend less time asleep and $68 \%$ said they feel stress and find it hard to sleep even after the lockdown. ${ }^{14}$

We suggest that the problem of disturbed sleep is an important issue for the short-term unemployed and especially for the LTU and those unable to work. We conjecture that that this may be causally linked to unemployment and joblessness. It is a problem because long sleep, like short sleep, is highly detrimental to an individuals' health, wellbeing and life prospects. Those who say they are unable to work experience even more sleep disruption than the LTU, which may play a role in their inability to find, or even search, for a job.

\footnotetext{
${ }^{13}$ Karin Brulliard and William Wan, 'The pandemic is ruining our sleep. Experts say 'coronasomnia' could imperil public health', Washington Post, $3^{\text {rd }}$ September 2020.

${ }^{14} \mathrm{https}: / /$ sleepstandards.com/sleep-habits-post-quarantine/\#Demographics
} 
Table 1. Hours of sleep in a 24-hour period (weighted). \%

$\begin{array}{lccccc} & \text { All } & \text { Workers } & \begin{array}{c}\text { Unemployed } \\ \geq 1 \text { year }\end{array} & \begin{array}{c}\text { Unemployed } \\ <1 \text { year }\end{array} & \text { Unable to work } \\ 1 & & & 0.22 & 0.17 & 0.37 \\ 2 & 0.13 & 0.11 & 0.78 & 0.40 & 1.21 \\ 3 & 0.28 & 0.17 & 2.52 & 1.22 & 3.47 \\ 4 & 0.79 & 0.49 & 8.47 & 4.35 & 10.19 \\ 5 & 3.10 & 2.48 & 10.10 & 8.68 & 13.34 \\ 6 & 7.59 & 7.63 & 23.72 & 22.97 & 22.15 \\ 7 & 23.27 & 25.71 & 19.52 & 22.87 & 12.84 \\ 8 & 29.25 & 33.12 & 26.93 & 28.72 & 22.77 \\ 9 & 27.63 & 25.22 & 5.13 & 5.63 & 4.45 \\ 10 & 4.42 & 3.17 & 3.71 & 3.13 & 4.82 \\ 11 & 2.29 & 1.30 & 0.29 & 0.26 & 0.38 \\ 12 & 0.15 & 0.08 & 1.32 & 1.06 & 2.56 \\ >12 & 0.72 & 0.34 & 0.71 & 0.55 & 1.29 \\ \text { Mean } & 0.38 & 0.19 & 6.95 & 6.99 & 6.72 \\ \% \text { short sleep } & 6.98 & 6.87 & 42.3 & 37.7 & 50.7 \\ \% \text { long sleep } & 35.2 & 36.6 & 6.1 & 5.0 & 9.2 \\ \text { N } & 3.5 & 0.6 & 46,908 & 44,147 & 145,659\end{array}$


Table 2. Weighted mean by employment status by three sleep measures

1) Hours of sleep in a $24 \mathrm{hr}$ period, 2009-2019 $(\mathrm{n}=2,033,672)$

All

Employee (48.3)

Self-employed (8.8)

Out of work $1+$ years $(3.0)$

Out of work $<1$ year (3.2)

Homemaker (6.5)

Student (5.8)

Retired (17.7)

Unable to work (6.8)

$\begin{array}{cc}\text { Short }(<7 \text { hours }) & \text { Long }(>9 \text { hours }) \\ 35.2 & 3.5 \\ 37.4 & 1.8 \\ 32.0 & 2.6 \\ 42.3 & 6.1 \\ 37.8 & 5.0 \\ 30.1 & 4.2 \\ 31.4 & 3.6 \\ 26.1 & 5.6 \\ 50.7 & 9.2\end{array}$

Numbers in parentheses are the overall weighted proportions in the population in our sample

2) Days of insufficient sleep in a month, 2008-2012 $(n=1,317,505)$

Employee

Self-employed

Out of work 1+ years

Out of work $<1$ year

Homemaker

Student

Retired

Unable to work \#days

8.98

7.90

9.77

8.78

8.53

8.89

4.85

13.90
$\% \geq 14$ days

29.0

24.8

33.1

29.1

27.7

28.4

14.8

50.0

3) Days of restless sleep in a fortnight, 2006, $(n=186,107)$

Employee

\#days

2.42

2.53

4.90

4.69

2.99

3.09

2.50

6.81
$\%=14$ days

7.6

8.4

22.9

20.6

10.9

9.7

9.7

34.7 
Table 3. Regression estimates of hours of self-reported sleep duration in a 24-hour period, 20092019.

(1) $-.0394(109.38)-.0391(108.20$

Age

$\operatorname{Age}^{2 *} 100$

Self-employed

Unemployed $\geq 1 \mathrm{yr}$

Unemployed $<1$ yr

Homemaker

Student

Retired

Unable to work

Refused

Year dummies

State \& month dummies

Personal controls

Constant

Adjusted R ${ }^{2}$

$\mathrm{N}$

Age minimum
.0468 (136.99)
Yes

No

No

Yes

Yes

.0241
(2) $.0465(136.11)$

(3)

$-.0314(72.86)$

$.0366(87.81)$

$.1443(37.47)$

$.0811(11.75)$

$.1263(17.82)$

$.1948(41.17)$

$.1499(21.06)$

$.2404(70.54)$

$-.0892(20.57)$

$.1610(12.21)$

Yes

Yes

Yes

7.6109

.0326

$2,029,005$

43

Personal controls include gender, marital status, labor force status, race, education, used a cell phone. Excluded category employees. Depression is not available in 2009. Estimated by OLS. 
Table 4. Probit estimates of short and long sleep probabilities in a 24-hour period, 2009-2019.

\begin{tabular}{|c|c|c|c|c|}
\hline \multirow[b]{3}{*}{ Age } & \multirow{2}{*}{\multicolumn{2}{|c|}{$\begin{array}{l}(1) \\
\text { Short sleep vs normal }\end{array}$}} & \multirow{2}{*}{\multicolumn{2}{|c|}{$\begin{array}{l}\text { (3) } \\
\text { Long sleep vs normal }\end{array}$}} \\
\hline & & & & \\
\hline & $.0098(26.89)$ & $.0179(44.65)$ & $-.0423(61.89)$ & $-.0304(40.32)$ \\
\hline $\mathrm{Age}^{2 *} 100$ & $-.0145(40.16)$ & $-.0228(57.94)$ & $.0410(63.70)$ & $.0307(43.58)$ \\
\hline Self-employed & $-.1277(36.09)$ & $-.1211(33.93)$ & $.1300(15.94)$ & $.1384(16.67)$ \\
\hline Unemployed $\geq 1 \mathrm{yr}$ & $.1942(31.36)$ & $.0984(15.72)$ & $.7045(64.48)$ & $.5854(52.59)$ \\
\hline Unemployed $<1$ yr & .0764 (11.97) & $.0004(0.07)$ & $.5016(42.13)$ & $.4067(33.58)$ \\
\hline Homemaker & $-.1042(24.58)$ & $-.1017(23.05)$ & $.3676(45.15)$ & $.3645(42.43)$ \\
\hline Student & $-.1300(20.09)$ & $-.1635(24.95)$ & $.0932(7.20)$ & $.0609(4.61)$ \\
\hline Retired & $-.1241(39.01)$ & $-.1351(42.14)$ & $.4156(65.68)$ & $.4106(63.87)$ \\
\hline Unable to work & $.5175(134.57)$ & $.3774(94.73)$ & $1.1249(165.53)$ & $.9567(135.75)$ \\
\hline Refused & $.0105(0.90)$ & $-.0561(4.61)$ & $.4985(24.21)$ & $.3982(18.45)$ \\
\hline Personal controls & No & Yes & No & Yes \\
\hline Constant & -.4033 & -.5919 & -.0803 & -1.0647 \\
\hline Pseudo $\mathrm{R}^{2}$ & .0251 & .0441 & .0701 & .0897 \\
\hline $\mathrm{N}$ & $1,955,876$ & $1,954,506$ & $1,375,800$ & $1,374,832$ \\
\hline Age maximum & 34 & 39 & & \\
\hline Age minimum & & & 52 & 50 \\
\hline
\end{tabular}

Notes; all equations include year, month and state dummies. Columns 2 and 5 add the following personal controls - gender, marital status, labor force status, race, education and used a cell phone. Excluded category=employees. T-statistics in parentheses. In the short sleep regressions, columns $1 \& 2$ the long sleepers are excluded while in the long sleep equations, columns $3 \& 4$, the short sleepers are excluded. 
Table 5. Regression estimates of insufficient sleep days, 2008-2012

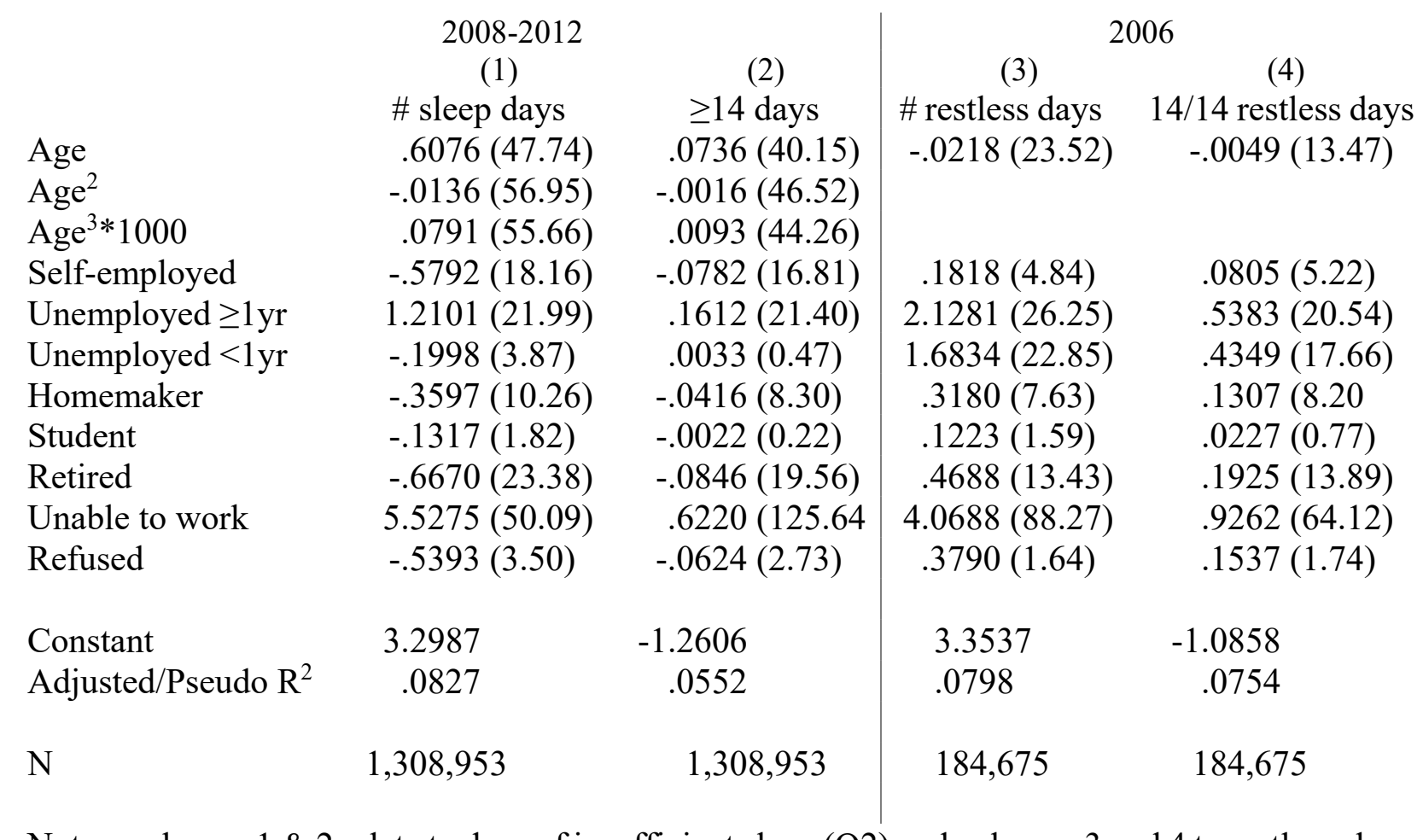

Notes: columns $1 \& 2$ relate to days of insufficient sleep (Q2) and columns 3 and 4 to restless sleep (Q3)

Controls in every equation include year, month and state, education, gender, marital status, cell phone and race. Columns $1 \& 3$ OLS, columns $2 \& 4$ probit. 


\section{References}

Abraham, K.G., J., Sandusky, K. and Spletzer, J.R. (2019). 'The consequences of long-term unemployment: evidence from linked survey and administrative data,' Industrial and Labor Relations Review, 72(2), pp. 266-299.

Afolalu, E.F. Ramlee, F. and Tanga, K.Y. (2018), 'Effects of sleep changes on pain-related health outcomes in the general population: A systematic review of longitudinal studies with exploratory meta-analysis,' Sleep Medicine Reviews, June, 39, pp. 82-97.

Aguiar, M., Hurst, E., and Karabarbounis, L. (2013). Time use during the Great Recession. The American Economic Review, 103(5), 1664-1696.

Altevogt, B.M. and H.R. Colten (2006). Sleep Disorders and Sleep Deprivation: An Unmet Public Health Problem. National Academies Press. Washington DC.

Antillón, M., Lauderdale, D.S. and Mullahy, J. (2015), 'Sleep behavior and unemployment conditions,' Economics \& Human Biology, 14, pp. 22-32.

Ásgeirsdóttir, T L and Ólafsson, S.P. (2015), 'An empirical analysis of the demand for sleep: Evidence from the American Time Use Survey', Economics \& Human Biology, 19: 265-274.

Asplund, M.D., Marnetoft, S.U., Selander, J. and Åkerström, B. (2005), 'Sleep in relation to sickness absence, unemployment and place of residence,' Sleep and Hypnosis, 7(1), pp. 22-28.

Basner, M., Fomberstein, K. M. Razavi, F.M., Banks, S., William, J. H., Rosa, R. R and Dinges, D. F. (2007) "American Time Use Survey: sleep time and its relationship to waking activities", Sleep, 30(9):1085. [PubMed: 17910380]

Bin, Y.S. Marshall, N.S. and Glozier, N. (2013), 'Sleeping at the limits: the changing prevalence of short and long sleep durations in 10 countries,' American Journal of Epidemiology, 177(8), pp. 826-833,

Bin, Y.S. Marshall, N.S. and Glozier, N. (2012), 'Secular trends in adult sleep duration: A systematic review, Sleep Medicine Reviews, 16(3), June 2012, pp. 223-230.

Blanchflower, D.G. (2020a), 'Is happiness U-shaped everywhere? Age and subjective well-being in 145 countries', Journal of Population Economics, forthcoming.

Blanchflower, D.G. (2020b), 'Unhappiness and age', Journal of Economic Behavior and Organization, August, 176, pp. 461-488.

Blanchflower, D.G. (2019), Not Working: Where Have All the Good Jobs Gone? Princeton University Press, Princeton, N.J.

Blanchflower, D.G. and Oswald, A.J. (2020), 'Trends in extreme distress in the USA, 1993-2019,' American Journal of Public Health, first published online $22^{\text {nd }}$ Augusts 2020. 
Blanchflower, D.G. and Oswald, A.J. (2008) 'Is well-being U-Shaped over the life cycle?', Social Science \& Medicine, 66(6), pp. 1733-1749

Blume, C., Schmidt, M.H. and Cajochen, C. (2020), Effects of the COVID-19 lockdown on human sleep and rest-activity rhythms', Current Biology, 30, R783-R801, July 20.

Buxton, O.M. and Marcelli, E. (2010), 'Short and long sleep are positively associated with obesity, diabetes, hypertension, and cardiovascular disease among adults in the United States,' Social Science \& Medicine, 71(5), pp. 1027-1036.

Cellini, N., Canale, N., Moini, G. and S. Costa (2020), 'Change in sleep pattern, sense of time and digital use during COVID-19 lockdown in Italy”, Journal of Sleep Research,

Centers for Disease Control \& Prevention (2011), 'Effect of short sleep duration on daily activities - United States, 2005-2008', Morbidity and Mortality Weekly Reports, 60(08), pp. 239-242.

Chattu, V.K., D. Manzar, S. Kumary, D. Burman, D.W. Spence, and S.R. Pandi-Perumal (2018), 'The global problem of insufficient sleep and its serious public health implications,' Healthcare (Basel), March, 7(1).

Colman, G., and Dave, D. (2013). Exercise, physical activity, and exertion over the business cycle. Social Science \& Medicine, 93, 11-20.

Council of Economic Advisors (2016), 'The long run decline in prime age male labor force participation rate', Washington DC.

Ellwood, D. (1984). Teenage unemployment, permanent scars or temporary blemishes?' in The Youth Labor Market Problem: Its Nature, Causes and Consequences, ed. R.B. Freeman and D. Wise, University of Chicago Press and NBER, Chicago.

Exelmans, L., Van den Bulck, J. (2016), 'Bedtime mobile phone use and sleep in adults', Social Science and Medicine, 148, pp. 93-101.

Falkingham, J., Evandrou, M., Qin, M. and Vlachantoni, A. (2020) "Sleeplessness in Lockdown: unpacking differences in sleep loss during the coronavirus pandemic in the UK",

Ferrie, J.E., Kivimäki, M., Tasnime N., Akbaraly, T.N., Tabak, A. Abell, J., Smith, G.D., Virtanen, M., Kumari, M. and Shipley, M.J. (2015), 'Change in sleep duration and Type 2 Diabetes: the Whitehall II Study, Diabetes Care, 38(8), pp. 1467-1472.

Gallicchio L. and B. Kalesan (2009),' Sleep duration and mortality: a systematic review and metaanalysis', Journal of Sleep Research, 18(2), pp. 148-58.

Gibson, M. and Shrader, J. (2018), 'Time use and labor productivity: the returns to sleep,' The Review of Economics and Statistics, 100(5), pp. 783-798 
Girschik J, L. Fritschi, J. Heyworth and F. Waters (2012), 'Validation of self-reported sleep against actigraphy', Journal of Epidemiology, 22(5), pp. 462-468.

Grandner M.A., J.L. Martin and N.P. Patel et al (2012), 'Age and sleep disturbances among American men and women: data from the U.S. Behavioral Risk Factor Surveillance System,' Sleep, vol. 35(3), pp. 395-406.

Gualano, M. R., Moro, G. L., Voglino, G., Bert, F. and Siliquini, R. (2020) "Effects of COVID19 Lockdown on Mental Health and Sleep Disturbances in Italy", International Journal of Environmental Research and Public Health, 4779

Hafner, M., Stepanek, M., Taylor, J., Troxel, W.M. and Christian van Stolk, C. (2017), 'Why sleep matters - the economic costs of insufficient sleep. A cross-country comparative analysis,' Rand Health Quarterly, 6(4): 11.

Huang, Y. and Zhao, N. (2020) "Generalized anxiety disorder, depressive symptoms and sleep quality during the COVID-19 outbreak in China: a web-based cross-sectional survey", Psychiatry Research, 288, 112954

Jike, M., Itani, O., Watanabe, N., Buys, D.J. and Kaneita, Y. (2018), 'Long sleep duration and health outcomes: A systematic review, meta-analysis and meta-regression', Sleep Medicine Reviews, 39, pp. 25-36.

Knabe, A., Rätzel, S.R., Schöb, R. and Weimann, J. (2010), 'Dissatisfied with life but having a good day:time-use and well-being of the unemployed,' Economic Journal, 120(547), pp. 867-889.

Knutson, K.L. and Turek, F.W. (2006), 'The U-shaped association between sleep and health: the 2 peaks do not mean the same thing,' Sleep, 29(7), pp. 878-879,

Kronholm E., Laatikainen T., Peltonen M., Sippola R., and Partonen T. (2011), 'Self-reported sleep duration, all-cause mortality, cardiovascular mortality and morbidity in Finland,' Sleep Medicine, 12, pp. 215-221.

Krueger, A.B., Cramer, J. and Cho, D. (2014), 'Are the long-term unemployed on the margins of the labor market?' Brookings Papers on Economic Activity, Spring, pp. 229-299

Kwok, C.S., Kontopantelis, E.; Kuligowski, G., Gray, M., Muhyaldeen, A., Gale, C.P., Peat, G.M., Cleator, J., Chew-Graham, C., Loke, Y.K., Mamas, M.A. (2018), 'Self-reported sleep duration and quality and cardiovascular disease and mortality: a dose-response meta-analysis,' Journal of the American Heart Association, 7(15).

Lauderdale, D.S., Knutson K.L, Yan, L.L., Liu, K. and Rathouz, P.J. (2008), 'Self-reported and measured sleep duration: how similar are they?', Epidemiology, 19(6) pp. 838-884. 
Liu, Y., A.G. Wheaton, D.P. Chapman, T.J. Cunningham, H. Lu, J.B. Croft (2016), 'Prevalence of healthy sleep duration among adults - United States, 2014,' Morbidity and Mortality Weekly Report, February 19, 65(6), pp. 137-141.

Liu Y., J.B. Croft and A.G. Wheaton, G.S Perry, D.P Chapman, T.W. Strine, L.R McKnight-Eily and L. Presley-Cantrell (2013), 'Association between perceived insufficient sleep, frequent mental distress, obesity and chronic diseases among US adults, 2009 BRFSS, BMC Public Health, 13(84).

Liu, Y., A.G. Wheaton, D.P. Chapman, T.J. Cunningham, H. Lu, J.B. Croft (2013), 'Sleep duration and chronic diseases among US adults age 45 years and older: evidence from the 2010 Behavioral Risk Factor Surveillance System', Sleep, 36(10), 1 October, pp.1421-1427.

Lockley, S.W., Cronin, J.W. Evans, E.E., Cade, B.E., Clark J Lee, Landrigan, C.P., Rothschild, J.M. Katz, J.T. Lilly, C.M., Stone, P.H., Aeschbach, D. and Charles A Czeisler, C.A. (2004), 'Effect of reducing interns' weekly work hours on sleep and attentional failures', The New England Journal of Medicine, 351, pp.1829-1837.

Machin, S. and Manning, A. (1999), 'The causes and consequences of long-term unemployment in Europe', Handbook of Labor Economics, edited by O. Ashenfelter and D. Card, North-Holland volume 3C, pp. 3085-3139.

Maeda, M., Filomeno, R., Kawata, Y., Sato, T., Maruyama, K., Wada, H., Ikeda, A., ISO, H. and Tanigawa, T. (2019). Association between unemployment and insomnia-related symptoms based on the Comprehensive Survey of Living Conditions: a large cross-sectional Japanese population survey,', Industrial Health, 57(6), pp.701-710.

Magee, L and Hale, L. (2012), 'Longitudinal association between sleep duration and subsequent weight gain: a systematic review', Sleep Medicine Review, 16, pp. 231-241.

Magee, C.A., Iverson, D.C. and Caputi, P. (2009), 'Factors associated with short and long sleep,' Preventive Medicine, 49(6), pp. 461-467.

Nichols, A. Mitchell, J. and Lindner, S. (2013), Consequences of long-term unemployment, Urban Institute.

Niekamp, P. (2018), ‘Economic conditions and sleep,’ Health Economics, 28, pp. 437-442.॥

Patel S.R., Ayas, N.T., Malhotra M.R., White, D.P., Schernhammer, E.S. Speizer, F.E., Stampfer, M.J., and Hu, F.B. (2004), 'A prospective study of sleep duration and mortality risk in women,' Sleep, 27(3), pp. 440-444.

Patel, S.R., Malhotra, A., Gottlieb, D.J., White, D.P. and Hu, F.B. (2006), Correlates of long sleep duration, Sleep, 29(7), July 2006, pp. 881-889.

Piper, A.T. (2016), Sleep duration and life satisfaction,' International Economic Review, 63, pp. 305-325. 
Roehrs T.F. Zoric, J, Sicklesteel, R. Wittig and T. Roth (1983), 'Excessive daytime sleepiness associated with insufficient sleep,' Sleep, 6(4), pp. 319-325.

Ruhm, C. (2005), 'Healthy living in hard times', Journal of Health Economics, 24(2), pp.341-363.

Shan Z., Ma, H., Xie, M. et al (2015), 'Sleep duration and risk of type 2 diabetes: a meta-analysis of prospective studies', Diabetes Care, 38(3), pp. 529-537.

Tamakoshi A, Ohno Y. (2004), 'Self-reported sleep duration as a predictor of all-cause mortality: results from the JACC study, Japan,' Sleep, 27, pp. 51-54.

Tang, K.Y., Fiecas, M., Afolalu, E.F. and Wolke, D. (2017), 'Changes in sleep duration, quality, and medication use are prospectively associated with health and well-being: analysis of the UK Household Longitudinal Study, Sleep, 40(3). https://doi.org/10.1093/sleep/zsw079

Virtanen, P., Janlertb, U. and Hammarström, A. (2013), 'Health status and health behavior as predictors of the occurrence of unemployment and prolonged unemployment', Public Health, 127(1), pp. 46-52.

Wang Y, H. Mei, J.R. Jiang et al (2015), 'Relationship between duration of sleep and hypertension in adults: a meta-analysis', Journal of Clinical Sleep Medicine, 11(9), pp. 1047-1056.

Wang D, W. Li, X. Cui et al (2016), 'Sleep duration and risk of coronary heart disease: A systematic review and meta-analysis of prospective cohort studies,' International Journal of Cardiology, 219, pp. 231-239.

Wheaton, A.G., Perry, G.S., Chapman, D.P, McKnight-Eily, L.R., Presley-Cantrell, L.R. Croft, J.B. (2011a), 'Relationship between BMI and perceived insufficient sleep among U.S. adults: an analysis of 2008 BRFSS data', BMC Public Health, 11:295

Wheaton A.G., Liu Y, Perry G.S., Croft J.B. (2011b), 'Effect of short sleep duration on daily activities - United States, 2005-8', Morbidity and Mortality Weekly Report, 60(8), pp. 239-42.

Wu Y., L. Zhai and D. Zhang (2014), 'Sleep duration and obesity among adults: a meta-analysis of prospective studies', Sleep Medicine, 15(12), pp. 1456-1462.

Yin J., Xiaoling Jin, X., Shan, Z., Li, S., Huang, H., Li, P., Peng, X., Peng, Z., Yu, K., Bao, W., Yang, W., Chen, X., and Liu, L. (2017), 'Relationship of sleep duration with all-cause mortality and cardiovascular events: a systematic review and dose-response meta-analysis of prospective cohort studies,' Journal of the American Heart Association, 6(9).

Zhai, L, H. Zhang and D. Zhang (2015), 'Sleep duration and depression among adults: a metaanalysis of prospective studies', Depression and Anxiety, 32(9), pp. 664-670. 

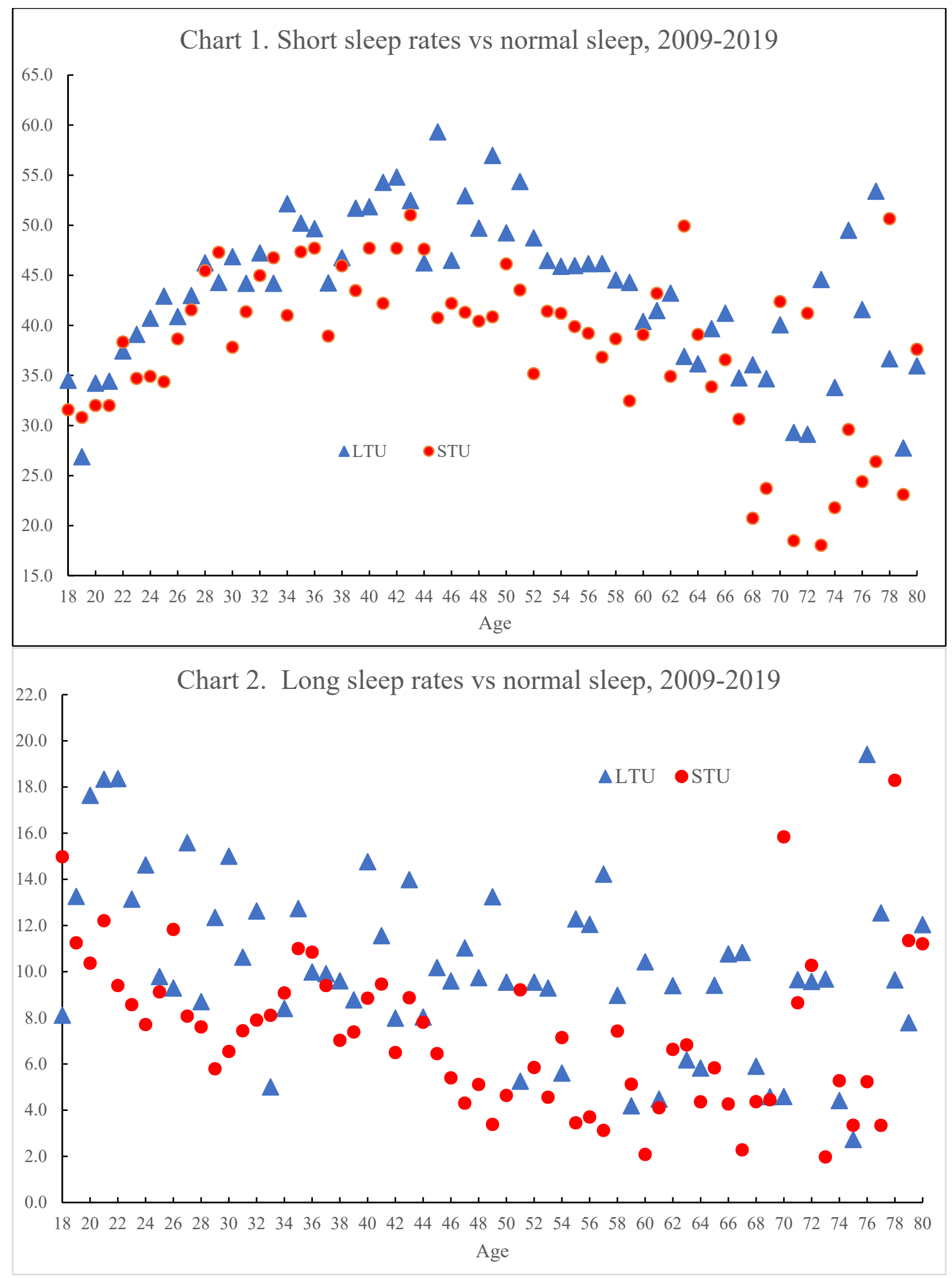
Chart 3. Insufficient days, 2008-2012

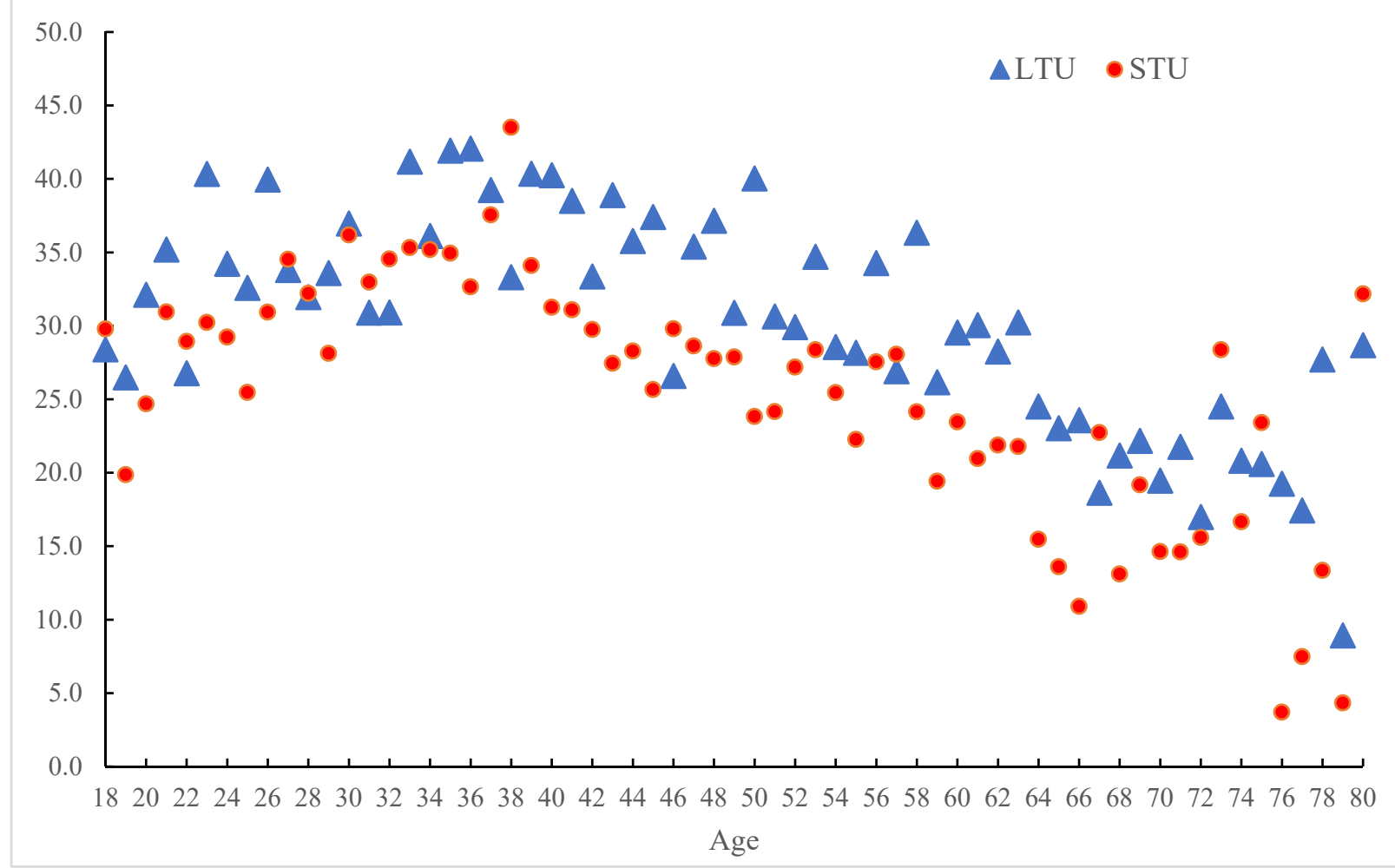

Chart 4. Short and long sleep vs normal for the unable to work, 2009-2019

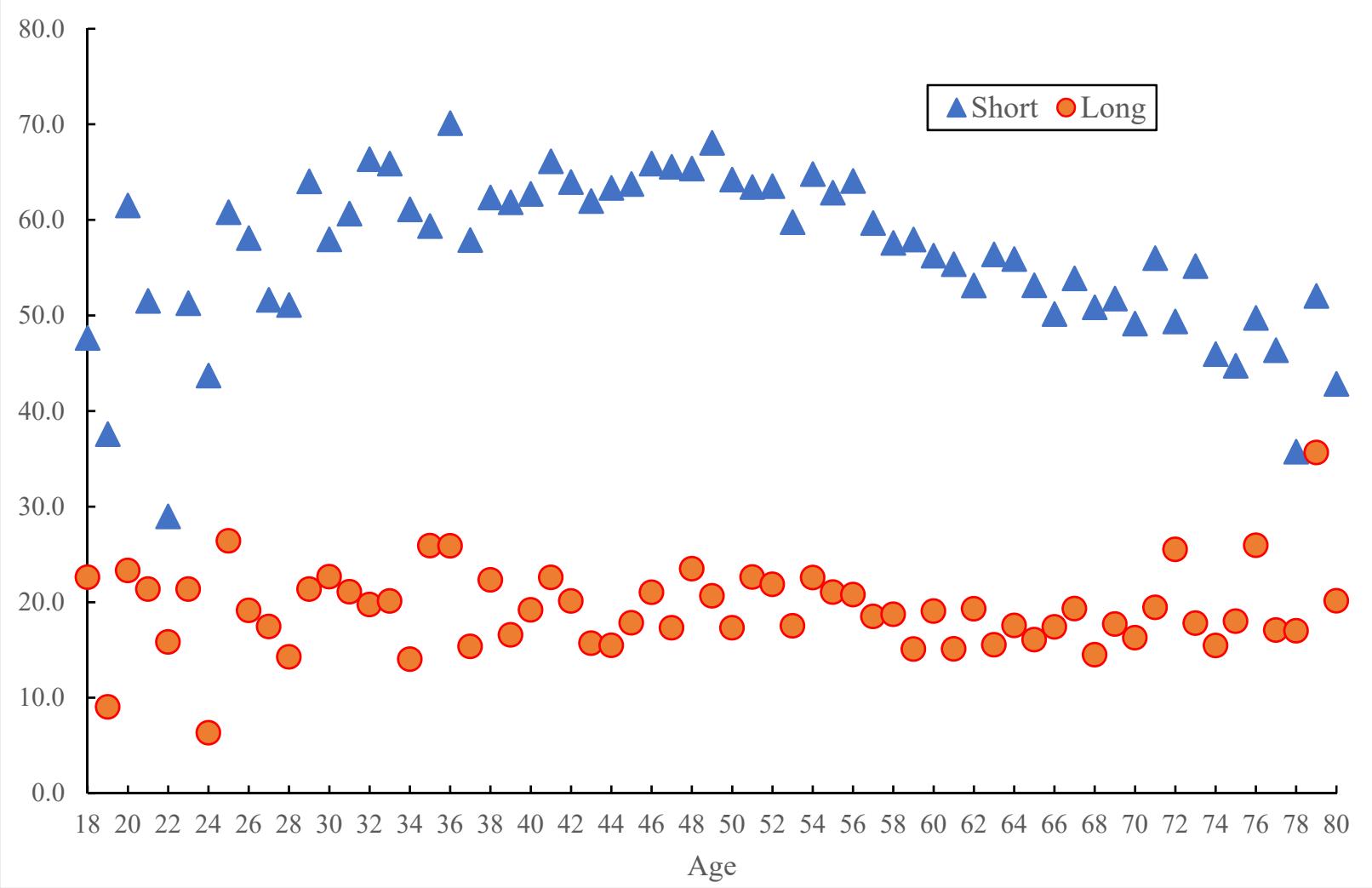


Appendix Lost sleep over worry, from Eurobarometer \#56.1 - regr v278 i.v6 age agesq male i.v145 i.v429 i.v428 note: $98 . v 429$ omitted because of collinearity

\begin{tabular}{|c|c|c|c|c|c|c|}
\hline Source | & SS & $d f$ & MS & Number of obs & $=$ & 15,782 \\
\hline & & & ---------- & $F(78,15703)$ & $=$ & 18.42 \\
\hline Model & 939.687528 & 78 & 12.047276 & Prob $>F$ & $=$ & 0.0000 \\
\hline Residual & 10269.1096 & 15,703 & .653958453 & R-squared & $=$ & D. \\
\hline------- & & & ----------- & Adj R-squared & $=$ & . \\
\hline Total & 11208.7971 & 15,781 & .710271663 & Root MSE & $=$ & 80 \\
\hline
\end{tabular}

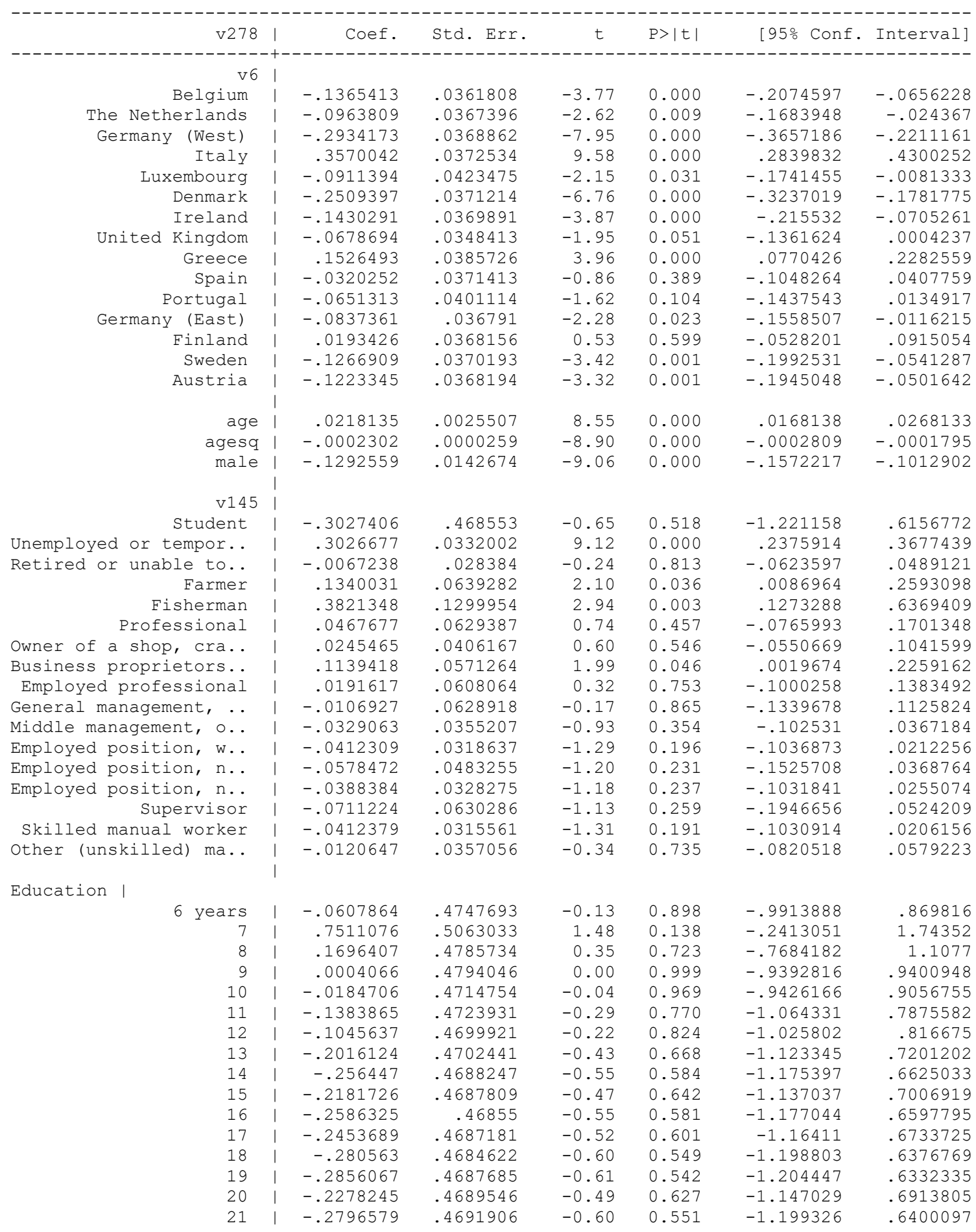




\begin{tabular}{|c|c|c|c|c|c|c|c|}
\hline 22 & I & -.2682026 & .4696063 & -0.57 & 0.568 & -1.188685 & .6522798 \\
\hline 23 & 1 & -.3580778 & .4699045 & -0.76 & 0.446 & -1.279145 & .5629891 \\
\hline 24 & I & -.2607747 & .4702448 & -0.55 & 0.579 & -1.182509 & .6609593 \\
\hline 25 & I & -.2437994 & .470623 & -0.52 & 0.604 & -1.166275 & .6786758 \\
\hline 26 & i & -.182478 & .4718983 & -0.39 & 0.699 & -1.107453 & .7424 \\
\hline 27 & । & -.2676052 & .4741111 & -0.56 & 0.572 & -1.196918 & .6617 \\
\hline 28 & i & -.1606453 & .4744755 & -0.34 & 0.735 & -1.090672 & .76938 \\
\hline 29 & I & -.2866545 & .4799497 & -0.60 & 0.550 & -1.227411 & .654102 \\
\hline 30 & I & -.212472 & .4748483 & -0.45 & 0.655 & -1.143229 & .71828 \\
\hline 31 & I & -.0240977 & .4868868 & -0.05 & 0.961 & -.9784518 & .9302 \\
\hline 32 & I & -.3232387 & .4843153 & -0.67 & 0.505 & -1.272552 & .6260 \\
\hline 33 & i & -.4373643 & .4890626 & -0.89 & 0.371 & -1.395983 & .52125 \\
\hline 34 & I & -.2499278 & .5005976 & -0.50 & 0.618 & -1.231157 & .73130 \\
\hline 35 & I & -.1017372 & .4874058 & -0.21 & 0.835 & -1.057109 & .85363 \\
\hline 36 & I & -.1876482 & .5102641 & -0.37 & 0.713 & -1.187825 & .81252 \\
\hline 37 & I & -.0894169 & .512741 & -0.17 & 0.862 & -1.094448 & .91561 \\
\hline 38 & I & .1578167 & .5129788 & 0.31 & 0.758 & -.8476807 & 1.1633 \\
\hline 39 years & 1 & -.1806805 & .5007414 & -0.36 & 0.718 & -1.162191 & .80083 \\
\hline till studying (see..) & I & 0 & (omitted) & & & & \\
\hline $\mathrm{v} 428$ & ! & & & & & & \\
\hline $\begin{aligned} v 428 \\
\text { Remarried }\end{aligned}$ & 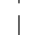 & .1369962 & .0501559 & 2.73 & 0.006 & 848 & .23 \\
\hline & i & .0842503 & .0261304 & 3.22 & 0.001 & .0330318 & .13 \\
\hline Unmarried. Currently.. & & - 0407905 & $\cdot 0<01304$ & 0.22 & . & .0330318 & $\begin{array}{r}.135468 \\
006578\end{array}$ \\
\hline Unmarried. Having ne.. & 1 & -.0407905 & .0241662 & -1.69 & 0.091 & -.0881591 & $.00657 \varepsilon$ \\
\hline Unmarried. Having pr.. & 1 & .1842126 & .0321293 & 5.73 & 0.000 & .1212355 & .24718 \\
\hline Divorced & I & .2450972 & .0281864 & 8.70 & 0.000 & .1898487 & .300345 \\
\hline Separated & 1 & .2772317 & .0528524 & 5.25 & 0.000 & .1736349 & .380828 \\
\hline Widowed & 1 & .115797 & .0271483 & 4.27 & 0.000 & .0625832 & .16901 \\
\hline Other (SPONTANEOUS) & I & .0586697 & .0626801 & 0.94 & 0.349 & -.0641905 & .18152 \\
\hline Refusal & I & .0170353 & .102813 & 0.17 & 0.868 & -.1844901 & .21856 \\
\hline cons & & .6583593 & .4710383 & 1.40 & 0.162 & -.26493 & 1.58164 \\
\hline
\end{tabular}

tab v278

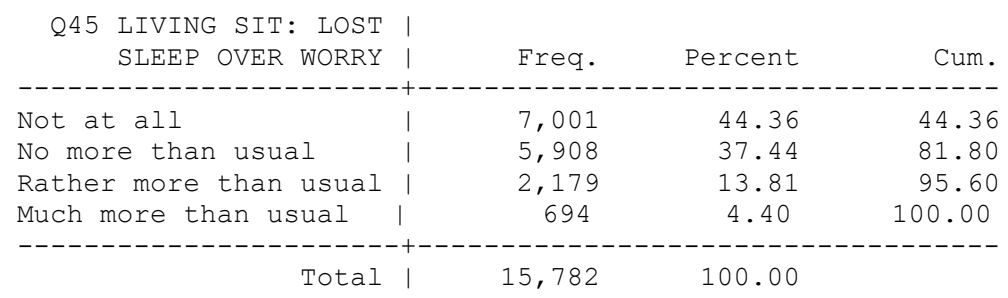

